\title{
The Influence of Network Literature on College Students' Ideological and Political Education
}

\author{
Kaiwei He \\ Sichuan Vocational College of Information Technology, China \\ 327566648@qq.com
}

\begin{abstract}
Keywords: Network literature; ideological and political education; college students; colleges and universities.
\end{abstract}

\begin{abstract}
The purpose of this paper is to study the impact of network literature on the ideological and political education of college students. Based on the previous literature, this paper expounded the characteristics of network literature and the relationship between college students and network literature. Then, we studied the ideological and political education resources in the network literature and the impact on college students. Finally, we put forward the corresponding countermeasures to strengthen the ideological and political education of college students. The results show that network literature has an important influence on college students. Therefore, we conclude that it is necessary to regulate network literature.
\end{abstract}

\section{Introduction}

With the popularity of the network, many of the network-related industries began to rise. In addition to online shopping, online literature is also quietly rising. Network literature is very popular among college students [2]. Under such a background, it is necessary to study the influence of network literature on the ideological and political education of college students. On the one hand, we should fully understand the ideological and political education factors in network literature, as well as the adverse effects of bad factors on readers; On the other hand, through the combination of theory and practice, we should promote the innovation of the ideological and political education model, and improve the students' immunity [4]. This can lead college students to read excellent works in online literature. Thus, by carrying out educational activities, we can effectively improve the ideological and political education of college students [1].

The theoretical work of ideological and political education has been advancing with the times [3]. With the popularity of the network, we should strengthen the theoretical work of research, to make it adapt to the new environment [5]. Since ancient times, excellent literature is a good carrier of Ideological and political education. It is responsible for some of the functions of ideological and political education. The study of network literature is conducive to enrich the carrier of ideological and political education, and innovative ideological and political education methods [6]. The ideological and political education of college students can adapt to the new environment. The contents and methods of ideological and political education of college students have been expanded [8]. It is of great practical significance to apply the excellent network literature to the ideological and political education of college students. The network literature will help to improve and enrich the knowledge structure of college students and improve their reading quality and appreciation ability. At the same time, it will help the ideological and political education workers change their ideas [7].

\section{State of the Art}

In foreign countries, network literature research is in the initial stage. The research mainly focuses on the definition and characteristics of the network literature itself [9]. The definition of online literature is divided into three categories. The first is Internet literature and online literature, which includes traditional literature on the internet. The second is electronic literature, which refers to the 
creation and dissemination of literary works by means of electronic equipment, such as radio, television and computer. The third is the computer text. In 1997, American critics Arthur published the book "Brake Text: Perspective of Computer Dynamic Literature." By analyzing the literature of electronic games, aesthetics and game elements, he proposed the concept of brake text. Subsequently, Professor Catherine Heller of the University of California proposed the general concept of network literature on the basis of the concept, and pointed out that this literary style has the characteristics of playfulness. Some scholars have studied the development of foreign Internet literature. It has the characteristics of early emergence and small scale. The Internet Literature in Europe and America has not developed into an industry. It sells electronic literature mainly through the internet. There are few studies on the influence of network literature on college students. Many studies are about the impact of the network on college students. The development of new media will change our communication habits. At the same time, human identity will be repositioned. Media literacy education can help students improve the ability to analyze media content, and provide an effective way for students to resist media infringement.

At present, the academic research on network literature has achieved certain results. However, the research results mostly focus on the concept, characteristics, and modes of communication and literariness of network literature [10]. These studies have analyzed and defined network literature from different perspectives, such as literature, computer technology, communication and social psychology. There are still few researches on the intersection of network literature and ideological and political education. There are many researches on the influence of network literature on college students. They all stay in the induction of the phenomenon of expression and the result of behavior, and lack systematic and thorough research. There are many vulgar and violent contents in the network literature works, which have negative influence on the formation of correct ideology and values of college students. This puts forward some challenges to the ideological and political education of college students. Excellent network literature, to a certain extent, also promotes the socialist core values, which has a positive guiding significance for college students. Under the goal of building a socialist cultural power, we should develop and use the ideological and political functions of the network literature, to guide the correct reading orientation of college students. It can promote the enthusiasm of college students' literary creation, and eliminate the adverse effects of bad network literature. This is very practical. Based on this, the author believes that it is necessary to draw on the achievements of research at home and abroad. On the basis of full investigation, this kind of literature should be integrated and make up for deficiencies, and find ways to solve the above problems. This can inject new vitality into the ideological and political education for college students.

\section{Methodology}

At the end of the 20th century, the Internet developed rapidly. Literature was integrated into the network, and network literature was born. Over the past two decades, the network has brought great influence to the literature. Network literature has developed into an important Internet industry. It not only changes the overall appearance and development pattern of Chinese literature, but also has a strong impact on the traditional literary ideas and creation and communication system. Contemporary literature is gradually transforming to digital media. Moreover, with the maturity of the business model, network literature has become an important cultural phenomenon that affects Internet users and even the vast numbers of TV users, movie users and gamers. As a result, more scholars have joined the ranks of online literature research.

According to CNNIC 35th China Internet development survey, as of the end of 2014, the total number of Internet users in China is reached 649 million, and the network literature users is reached 293 million. Internet literature users grew by nearly 20 million at the end of 2013 . Among the 649 million netizens in China, the proportion of young people under 25 years of age is 277 million, accounting for $42.7 \%$ of the total number of Internet users. Thanks to the development of the Internet and the promotion of smart phones, network entertainment has been greatly developed. In network 
entertainment behavior, the youth group has always been in the forefront of the overall Internet users. In 2014, according to the national youth online behavior research report, network literature in the youth network entertainment behavior ranks fourth. The popularity of online entertainment applications among adolescents is shown in Table 1.

Table 1 . The popularity of online entertainment applications among adolescents

\begin{tabular}{|c|c|c|c|c|c|c|c|}
\hline $\begin{array}{c}\text { Entertainment } \\
\text { applications }\end{array}$ & $\begin{array}{c}\text { Primary } \\
\text { school } \\
\text { students }\end{array}$ & $\begin{array}{c}\text { Middle } \\
\text { school } \\
\text { student }\end{array}$ & $\begin{array}{c}\text { College } \\
\text { student }\end{array}$ & $\begin{array}{c}\text { Not } \\
\text { student }\end{array}$ & $\begin{array}{c}\text { Adolescent } \\
\text { population }\end{array}$ & $\begin{array}{c}\text { Netizen } \\
\text { overall }\end{array}$ & Difference \\
\hline Network music & $65.7 \%$ & $78.6 \%$ & $81.6 \%$ & $77.9 \%$ & $77.5 \%$ & $73.7 \%$ & $3.8 \%$ \\
\hline Network game & $70.9 \%$ & $66.5 \%$ & $59.4 \%$ & $62.2 \%$ & $64.3 \%$ & $56.4 \%$ & $7.9 \%$ \\
\hline Network video & $55.0 \%$ & $67.0 \%$ & $79.8 \%$ & $71.7 \%$ & $69.4 \%$ & $66.7 \%$ & $2.7 \%$ \\
\hline $\begin{array}{c}\text { Network } \\
\text { literature }\end{array}$ & $19.9 \%$ & $49.6 \%$ & $52.4 \%$ & $49.0 \%$ & $46.9 \%$ & $45.3 \%$ & $1.6 \%$ \\
\hline
\end{tabular}

As can be seen from Table 1, the popularity of online literature in the student group was significantly higher than the average Internet users. Among them, the popularity rate of Internet literature of college students is the highest. According to the survey, $90 \%$ college students have experience in reading online literature. Nearly $1 / 4$ of college students read online literature every day, and nearly $1 / 10$ of them read more than two hours a day.

According to iResearch's "China Network Literature Industry Report 2015", in online literature users, young men accounted for $56.4 \%$, and female users accounted for $43.6 \%$. In terms of educational qualifications, college capital accounted for nearly half, reaching $49.1 \%$, and college educated users also reached $27.6 \%$. The age distribution of online literature users in 2015 is shown in Figure 1. The distribution of user education in online literature in 2015 is shown in Figure 2.

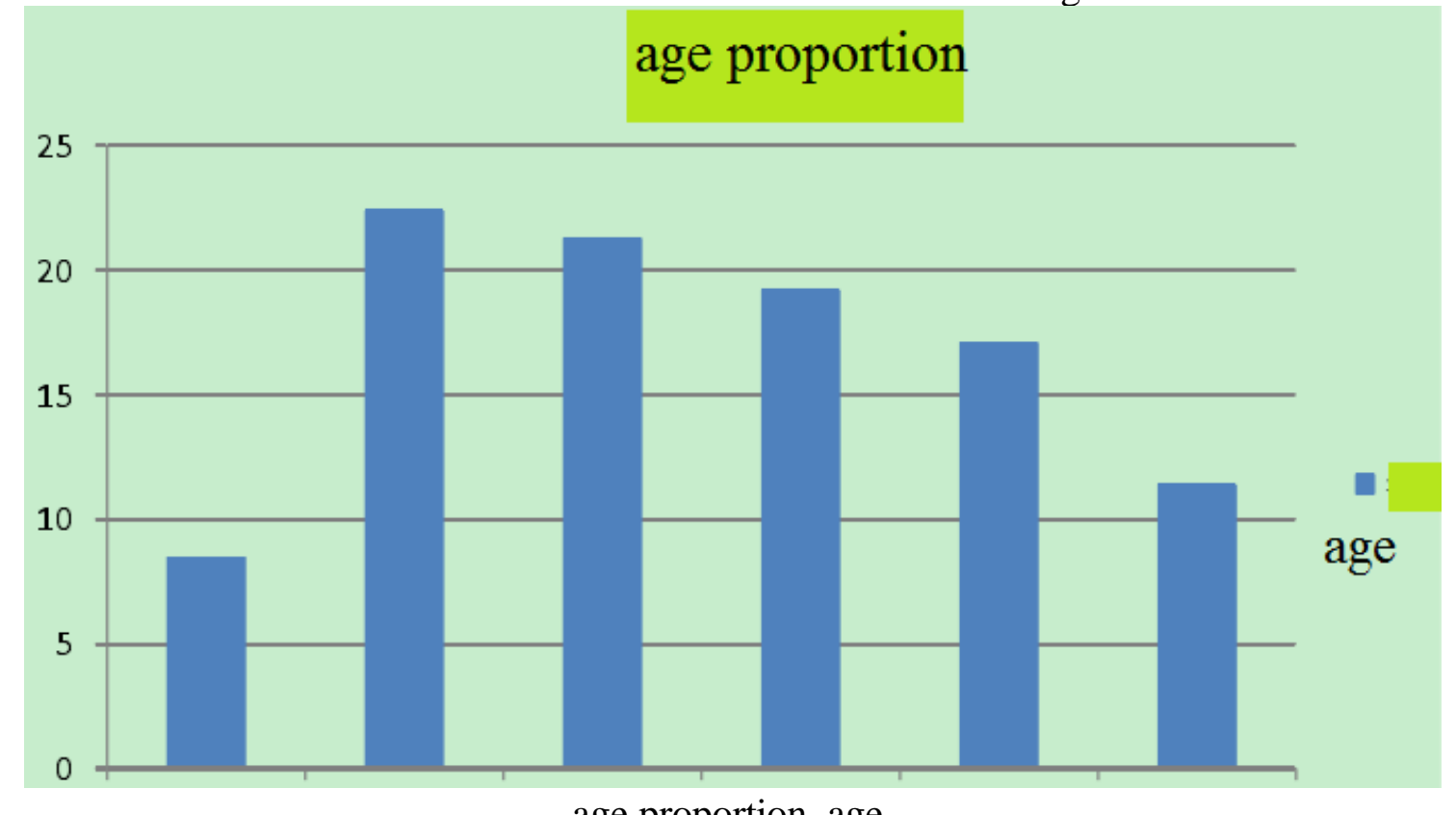

age proportion, age.

Figure 1. The age distribution of online literature users in 2015 


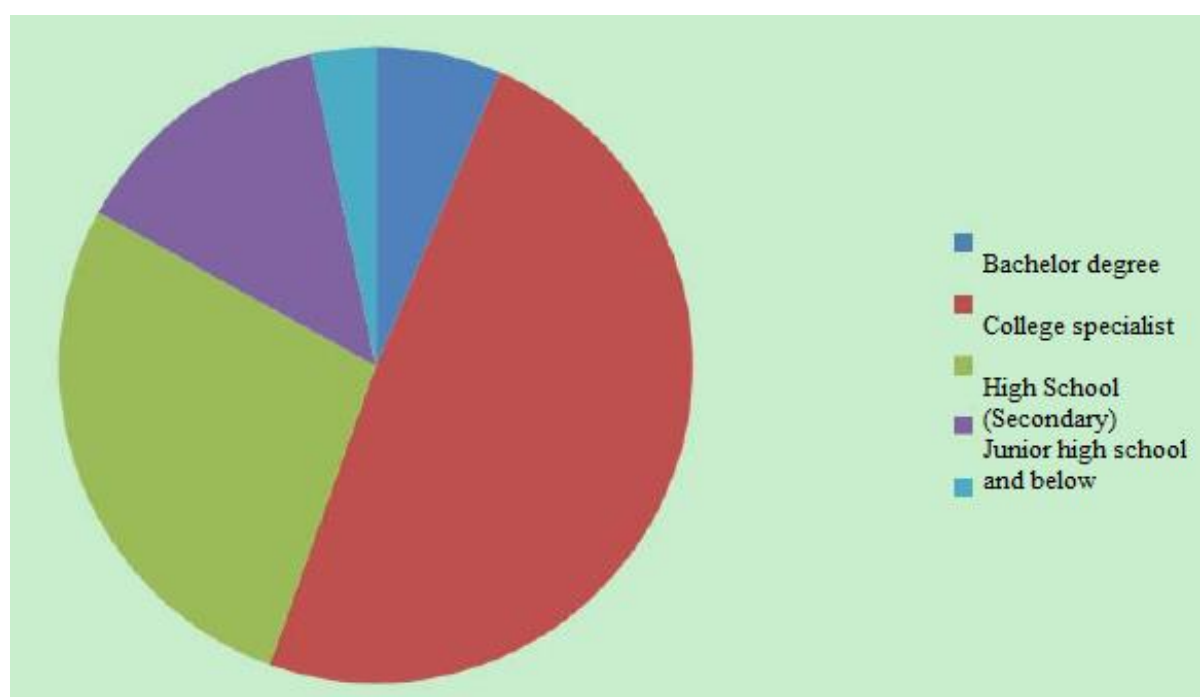

Figure 2. The distribution of user education in online literature in 2015

Master degree or above, undergraduate college under college, high school (technical secondary school) senior high school (technical secondary school), junior high school and below junior high school and below.

From these professional data and related research results, we can easily find that young people, especially college students, have become the most loyal group of network literature users. The favorite topics of college students' favorite literary works are also relatively concentrated. According to the data released by Ereli Consulting, boys are most interested in reading works of fantasy, fairy chivalrous, martial arts and historical themes, while girls prefer works of youth school, romance and fantasy. From the two aspects of objective and subjective, the reasons why college students prefer Internet literature can be divided into the following two points:

First, it is easy to access the network literature. From an objective point of view, network literature has been able to achieve tremendous development, and the convenience of reading is one of the main reasons. Readers generally read traditional literature by buying or borrowing books, which results in higher reading costs. However, the economic situation of students is relatively poor, which makes traditional literature difficult to quickly popular and sell well, and the range of communication is limited. Because of the richness and sharing of resources, both in the network and in reality, network literature is spread by the speed and the wide range. College students are more receptive to electronic products. Mobile phones are overtaking computer as a preferred device for Internet access among young people. The progress of electronic equipment has provided great convenience for college students to obtain network literature.

Second, it caters to the psychological needs of college students. The main groups of creators and readers of online literature are teenagers. The college students have a lot of free time. They will choose a variety of entertainment to recreation time. Network literature and its strong entertainment is known, so the network literature has become a good choice. The content of network literature caters to the psychological needs of college students. Network literature has its own unique characteristics. Its content can be divorced from reality. In the reading process, the reader is caught in the fictional world of literature. People's desires are released and found solace in online literature. It is like a dream machine, to meet a variety of dreams. In addition, the language of online literature is straightforward and humorous, which shows that it is different from the traditional literature. These are closer to the daily life of college students, so the network literature can be popular among college students. For college students, humorous words are more attractive than history books. Compared to recreational activities, there are also many college students who say that reading online literature can broaden their horizons and gain useful information. 


\section{Result Analysis and Discussion}

As an important form of literature in the Internet age, network literature has no doubt about its popularity among young people. At present, the commercial atmosphere of network literature is popular. People pay too much attention to the entertainment function of network literature, but ignore the social benefit. There is a lack of Ideological and political education in network literature, which has a negative impact on college students. Therefore, we should learn the positive energy in the network literature. The ideological and political education of college students is an urgent task. To this end, the government, society and schools must act.

\subsection{Occupying the position of network public opinion with socialist core values}

The content of the socialist core values comprehensively covers three levels of the individual level, the social level and the national level, which are in line with the values of the current Chinese society. It points out the direction for the progress of socialism. In the era of network information, the network platform is a new battlefield of the ideological and political education. Occupying the position of network public opinion with the socialist core values plays an important role in guiding the values. The early development of the network has a lot of disadvantages, such as lack of network system, network moral anomie, spread unhealthy contents of various sex and violence, which caused a great negative impact on the healthy growth of young people. We must create a good network environment to improve people's recognition of the socialist core values under the network environment. We should improve the network security protection technology, and strengthen the supervision and management of the network. This provides a good ecological environment for the cultivation of socialist core values on the internet. In addition, the special network dissemination platform is also an important way for the socialist core values to occupy the position of network public opinion. Traditional literature is serious literature. In a sense, it is also classical literature. The emergence of network literature easily collapsed the censorship of newspaper and book. Most of the creative subjects of network literature are young people. Many Internet writers have either graduated from college or started writing literature on the Internet at college. At present, many college students will be engaged in literary and art creation in the future. The combination of the socialist core values and the network literature will enhance the permeability and communication power of the socialist core values, and carry out ideological and political education for college students. It laid a solid foundation for the socialist core values to occupy the network of public opinion positions.

\subsection{Strengthen the supervision of the network literature industry}

The network literature has some bad influence on college students' ideology. There are network writers own responsibility, but also has the responsibility of poor supervision. The good operation of ideological and political work in colleges and universities cannot be separated from the support of the state and the whole society. Network literature is an important part of socialist culture. The prosperity of socialist culture cannot be separated from the development of network literature. We should not only pay attention to the economic benefits of network literature, but also pay more attention to its social benefits. Therefore, the state and society should strengthen the guidance of the network literature industry and take the road of sustainable development. China's Internet development started slowly, but the development is very rapid. At present, China has nearly 700 million of Internet users. This is a remarkable achievement. However, the rapid development has also exposed some problems. A wide variety of literary websites, forums and post bars have appeared on the Internet, and many websites are extremely disorganized. In recent years, although the community has been calling for speeding up the promotion of network legislation, network literature website special management mechanism has not really established. The quality of the network literature is uneven. It is very difficult for the relevant network regulators to find the problematic works from the massive works. Therefore, the network regulators should strengthen the supervision of the network literature technology. The network supervision department should apply the search and filtering technology to the supervision of the 
network literature. Through keyword search, regulators can lock those bad content works, and effectively investigate and punish them.

\subsection{Strengthen the cultural construction of university campus}

The construction of campus culture is of great significance to strengthen the ideological and political education of college students. Campus environment has many characteristics, such as comprehensiveness, permeability and guidance. It not only includes teaching activities and extracurricular activities, but also includes learning atmosphere, teaching atmosphere and campus ethos. For colleges and universities, the most important thing is to improve campus culture. The influence of campus culture on students is silent. College students are virtually influenced by the campus atmosphere. It is of great significance for training college students' will and shaping their personality. As the last platform for students to enter the society, the ideological and political education is very important. Internet literature has inevitably infiltrated the university campus. The phenomenon of merging with campus culture has promoted the prosperity of campus literature to a certain extent. However, there are many negative influences on Internet literature. Good campus culture can restrict these negative influences. Campus spirit is the core of campus culture construction. To build a good campus spirit and culture, we must build a good school spirit. Harmonious and orderly school spirit can ease the negative emotions of college students, correct the bad habits of college students, and cultivate their good ideological and moral qualities.

\section{Conclusion}

Based on the previous academic achievements, this paper expounds the connotation and characteristics of network literature, and explores its influence on the ideological and political education of college students. Then, we put forward the corresponding policy. Network literature contains a wealth of ideological and political education resources. Good literary works can play a guiding role. It can be used as an effective way to educate college students. However, some bad network literature will bring a lot of negative impact to readers. As the most active group in the society, college students are most affected by the impact of the internet. The development of standardized network literature is helpful to cultivate good reading habits and creative enthusiasm of college students. The construction of socialist core values is not something that can be accomplished in a short time. To this end, it requires long-term efforts by the government, society and schools.

Through the study of the impact of network literature on college students, we have seen the adverse effects of network literature on Ideological and political education. Therefore, we should try to explore the valuable resources that can be used for reference in the ideological and political education of Internet literature, and guide the ideological and political education of college students with the socialist core values. At the same time, we should enrich the construction of campus culture, strengthen the supervision of the network literature industry, and provide a good learning environment for college students. While improving their comprehensive qualities, college students should engage in literary and artistic creation to spread socialist core values.

\section{References}

[1]. Chen, Xiao Li, M. Department, and C. N. University. "Problem Analysis on the Ideological and Political Education for College Students." Journal of Hubei Correspondence University 13.2(2016):45-49.

[2]. Gan, Zhong Tao, and X. N. University. "The Challenges and Measures to the Ideological and Political Education of the College Students under the Network Culture Context." Journal of Hubei Correspondence University (2016):118-123.

[3]. Hu, Yinping, and I. Department. "Expansion and Realization Path of Developing Ideological and Political Education of Shanghai College Students from the Perspective of Shanghai Regional Culture." Journal of Baotou Vocational \& Technical College 10.2(2016):82-87. 
[4]. Li, Zhang, and C. University. "The Strategies for the Ideological and Political Education of College Students under the Background of New Media." Journal of Hebei Energy Institute of Vocation \& Technology 14.2(2016):131-135.

[5]. Tian, Zi Rui. "Reflection on Strengthening the Ideological and Political Education of College Students in the Age of Micro-blog and WeChat." Education Teaching Forum 23.1(2016):133-138.

[6]. Wang, Yong Gui, S. A. Office, and X. N. University. "Research on the Effective Ways of Life Education in the Ideological and Political Education of College Students." Journal of Hubei Correspondence University 57.3(2015):231-237.

[7]. Wang, Jiasheng. "The Combination of virtuality and Reality-Effective Implementation of Ideological and Political Education of College Students under the New Media Environment." Science Education Article Collects 25.1(2015):33-46.

[8]. Yan, Gou. "Research of Influence of Internet Hot Issues on the Ideological and Political Education for College Students." Journal of Hubei Correspondence University 12.1(2016):71-74.

[9]. Zhang, Lina, W. Li, and Q. Zhang. "Research on the Performance Evaluation Model and System of Ideological and Political Education for College Students." International Journal of u- and eService, Science and Technology 8(2015):13-16.

[10]. Zhou, Wen Fei, and L. Li. "The Research on the Function of College Students' Ideological and Political Education to College Students' Employment." Open Cybernetics \& Systemics Journal 9.1(2015):1806-1813. 